\title{
Potential microRNA-related Targets for Therapeutic Intervention with Ovarian Cancer Metastasis
}

\author{
ULRICH H. WEIDLE ${ }^{1}$, FABIAN BIRZELE ${ }^{2}$, GWEN KOLLMORGEN ${ }^{1}$ and ADAM NOPORA ${ }^{1}$ \\ ${ }^{1}$ Roche Innovation Center Munich, Roche Diagnostics GmbH, Penzberg, Germany; \\ ${ }^{2}$ Roche Innovation Center Basel, F. Hofman La Roche, Basel, Switzerland
}

\begin{abstract}
Treatment of disseminated epithelial ovarian cancer $(E O C)$ is an unmet medical need. Therefore, the identification along with preclinical and clinical validation of new targets is an issue of high importance. In this review we focus on microRNAs that mediate metastasis of EOC. We summarize up-regulated metastasis-promoting and down-regulated metastasis-suppressing microRNAs. We focus on preclinical in vitro and in vivo functions as well as their metastasisrelated clinical correlations. Finally, we outline modalities for therapeutic intervention and critical issues of microRNAbased therapeutics in the context of metastatic EOC.
\end{abstract}

In 2016, approximately 22,000 women were diagnosed with ovarian cancer in the U.S. and about 14,000 have died from this disease (1). Ninenty percent of ovarian carcinomas are epithelial tumors referred to as epithelial ovarian cancer (EOC) with subtypes such as serous (more than 50\%), endometrioid, clear cell, mucinous and undifferentiated or unclassifyable tumors (1). Other types of ovarian cancer are germ cell and sex-cord stromal tumors arising from eggprducing oocytes or from estrogen and progesterone producing stromal cells. After surgical debulking, EOC patients are treated with intravenous and/or intraperitoneal platin or taxane-based chemotherapy; however, patients typically relapse within two years of the initial treatment $(2,3)$. For treatment of platinum-sensitive recurrent ovarian cancer, the

This article is freely accessible online.

Correspondence to: Adam Nopora, Roche Innovation Center Munich, Roche Diagnostics GmbH, Nonnenwald 2, D-82372 Penzberg, Tel: +49 8856602552, e-mail: adam.nopora@roche.com

Key Words: Antisense oligonucleotides, ascites fluid, epithelial mesenchymal transition, epithelial ovarian cancer, extracellular matrix, locked nucleic acids, mesothelial cells, peritoneal dissemination, review. targeted agent, Avastin, a humanized antibody directed against vascular endothelial growth factor, isoform A, (VEGF-A) has been approved in combination with chemotherapy (4). Numerous other agents such as: tyrosine kinase inhibitors that target both VEGFR and other proangiogenic receptors, a peptide-Fc fusion protein that inhibits binding of angiopoietins 1 and 2 to the Tie- 2 receptor, several poly ADP ribose polymerase (PARP) inhibitors and a cytotxic agent targeting the $\alpha$-folate receptor are under clinical investigation $(5,6)$. Very recently, FDA has approved rucaparib, a PARP inhibitor, for treatment of breast cancer 1/2 mutation (BRCA) ovarian cancer that has not responded to at least two chemotherapy drugs (7). In order to further highlight pathways and targets for therapeutic intervention, we review the role of microRNAs (miRs) in metastasis of EOC.

\section{Metastasis}

EOC is a tumor entity arising from tissue on the surface of the ovary that can metastasize via transcoelomic, hematogenous and lymphatic routes (8). In this review we will focus on the role of miRs in transcoelomic dissemination, which is generally the preferred mechanism of metastasis of EOC. The process of metastasis starts with the shedding of single cells or multicellular aggregates (spheroids) into the peritoneum after expression of anoikis-inhibiting proteins and morphological conversion by epithelial-mesenchymal transition (EMT) $(2,9)$. Several mechanisms of suppressing an immune response against disseminating ovarian cancer cells are implemented by the tumor cells, such as secretion of Fas-ligand, which induces apoptosis in Fas-expressing immune cells (10). Tumor cells are passively transported by ascitic fluid which contains an abundant source of metastasispromoting factors and its formation is enhanced by tumor-cell secreted VEGF (11). Eventually nodules are formed in the omentum and peritoneum originating from interactions of tumor cells with the mesothelium $(2,8,9)$. The mesothelium is composed of a single layer of specialized epithelial cells 
with luminal microvilli that are attached to a basement membrane composed of collagens of type I and IV, fibronectin and laminin $(2,8,9)$. A number of interactions have been shown to be crucial for adhesion of tumor cells to mesothelial cells, for example: the interaction of tumor cell Integrin $\beta 1$ with fibronectin expressing mesothelial cells, mesothelial cell expressed vascular cell adhesion molecule (VCAM) with tumor-cell $\alpha 4 \beta 1$, and tumor cell expressed cluster of differentiation 44 (CD44) with hyaluronic acid on mesothelial cells (12-14). An essential step for colonization of secondary sites is the recruitment of endothelial cells (EC) by tumor-secreted pro-angiogenic factors (15). In addition, adipocytes which are a major constituent of the microenvironment of ovarian cancer have been shown to promote tumor growth and metastasis (16). There is evidence that cancer stem cell (CSC)-related subpopulations are involved in ovarian cancer metastasis and chemotherapy resistance $(17,18)$. In this review we focus on the role of miRs in the metastatic cascade of EOC in order to identify possible new targets with an impact for treatment of EOC. Angiogenesis is one essential aspect for ovarian cancer metastasis, however it is also involved in other steps of the pathogenesis of ovarian cancer, therefore we will not discuss miRs modulating angiogenesis in detail in this review (19).

\section{microRNA}

miRs are evolutionary-conserved small non-coding RNAs comprising of 18-25 nts (20-23). They interact with their target mRNAs through a 6-8 nt seed sequence at their 5 'end by base-pairing with a complementary sequence often located in the 3'-untranslated region (3'-UTR) of their target mRNA, which results in their cleavage, degradation or inhibition of translation (22). Approximately 1,000 miR genes have been identified. After transcription by RNA polymerse II, miRs undergo a number of processing steps, which include capping at their 5'end, polyadenylation at their 3'end, cleavage and sometimes splicing. The corresponding genes can be located in exons, introns or intergenic regions (24). miRs are synthesized as precursor mRNAs that are processed to mature miRs by several sequential steps. Pri-miRNA, the hairpin-shaped primary transcript comprising several hundred nts is first converted to double-stranded, hairpin-shaped pre-miRNA by the action of RNAse III enzyme DROSHA and its cofactor DiGeorge syndrome critical region 8 (DGCRG8) (25). Pre-miRNA (60$70 \mathrm{nts}$ ) is exported to the cytoplasm by Exportin 5 through a nuclear pore (26) and subsequently its loop is cleaved by RNAse DICER and TAR RNA binding protein (TRBP) resulting in a miRNA duplex $(27,28)$. In the next step the miRNA duplex is incorporated into the RNA-induced silencing complex (RISC). Processing of the 18-25 nts miRmiR* duplex is mediated by the argonaute family of proteins
(AGO) in conjunction with several co-factors. After unwinding and strand selection, the mature miR can interact with its cognate target(s) and excert its action as described above. An alternative mechanism for generation of functional miRs has emerged (29). In this context, mirtrons arise from spliced out introns and circumvent cleavage by the microprocessor complex (29). Since miRs can hit several targets, their inhibition may result in modulation of several distinct pathways and disturb regulatory networks (30).

miRs are involved in several steps of the pathogenesis and dissemination of cancer $(31,32)$. A crucial step in this context was the demonstration of involvement of miR-15a and miR-161 in the pathogenesis of B-cell chronic lymphocytic leukemia (B-CLL) $(33,34,35)$. Tumor suppressors are frequently deleted in B-CLL on chromosome 13q14, a locus containing miR-15a and miR-16-1 (33-35). In a proof-of-concept experiment, deletion of miR-15a and miR-16-1 cluster in mice recapitulated the human disease phenotype of B-CLL in mice (33-35) by circumventing the cleavage of the mRNA coding for the antiapoptotic protein $\mathrm{Bcl} 2$. miRs are involved in several steps of the pathogenesis of ovarian cancer $(36,37)$. In this review we focus on their involvement in metastasis of EOC and their role as possible targets for therapeutic intervention.

\section{Metastasis-promoting miRs with Preclinical In Vivo Efficacy}

In this category we discuss miRs $-182,-205$ and -141 .

miR-182. Anti-miR-182 treatment inhibits invasion, proliferation and anchorage-independent cell growth of EOC cell lines SKOV-3, HEY and OVCAR3, as well as the growth and size of tumors resulting from i.p. injected OVCAR3 cells (38). The impact of miR-182 on EOC cell metastasis was investigated by intrabursal implantation of pellets derived from OVCAR3 cells, where anti miR-182 treatment resulted in a five-fold reduction of nodules in peritoneal organs compared to controls (38). Another study investigated the role of miR-182 in T29 and T80 (surface epithelium), FTE 187 (fallopian tube) and HEY, SKOV3 and OVCAR3 (EOC) cell lines, and showed that miR-182 increased transformation and invasiveness, but had no impact on proliferation. In an experimental metastasis model with SKOV-3 cells overexpressing miR-182 and corresponding controls, significantly larger and increased number of lung metastases were observed with the transfectants (39). miR182 exerts its metastasis-promoting effects through downregulation of BRCA1 and concomittant up-regulation of high-mobility group AT-hook2 (HMGA2) and further through negative regulation of metastasis suppressor 1 (MTSS1) as direct targets (Figure 1). HMGA2 is an oncogenic transcription factor with a documented role in promoting EMT during EOC progression (40). MMTS1 has 


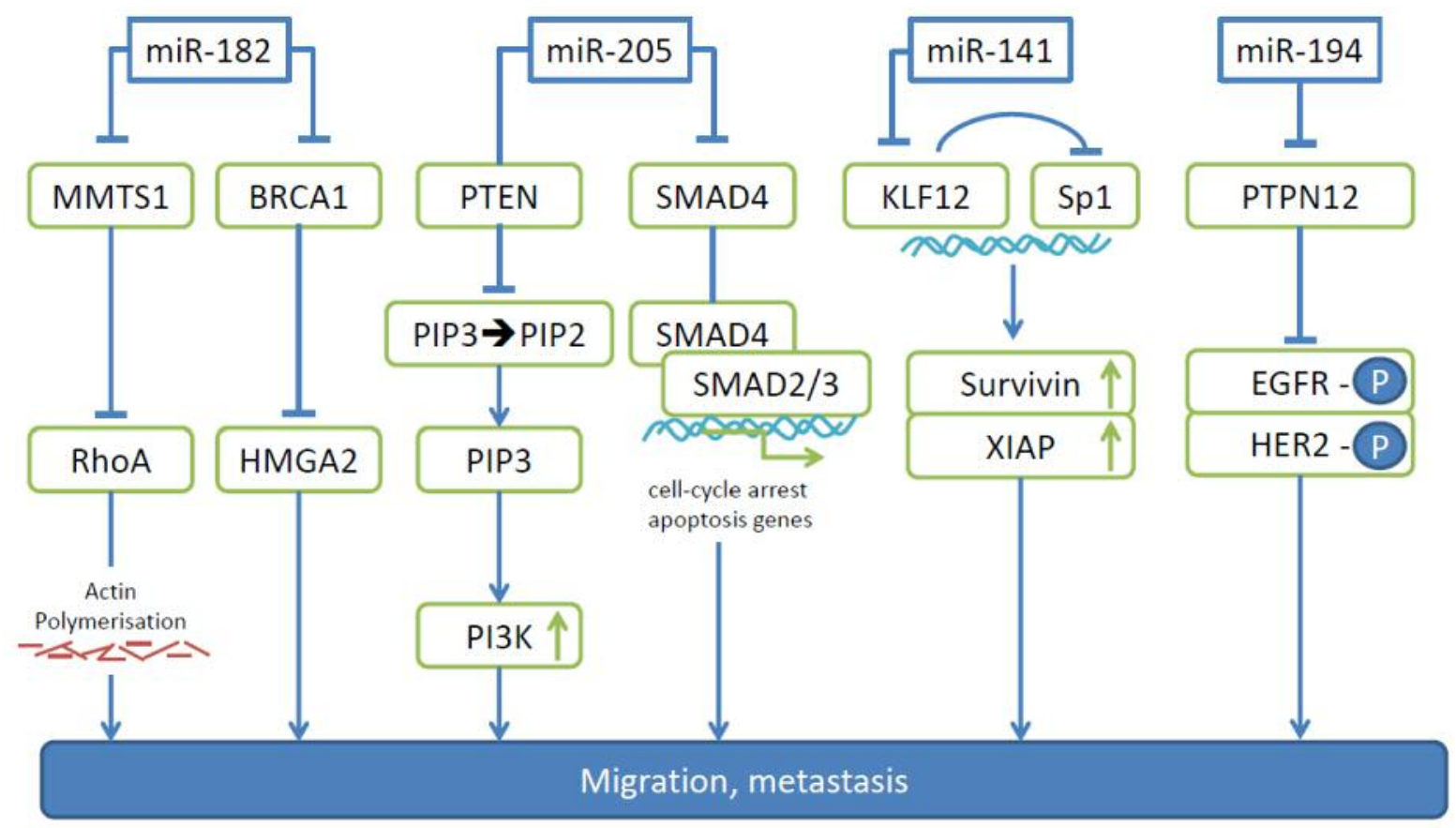

Figure 1. The role of microRNAs -182, -205, -141 and -194 as mediators of migration and metastasis in ovarian carcinoma. Pathways leading to migration and metastasis of ovarian carcinoma activated by individual miRs are indicated. BRCA1, Breast cancer antigen1; EGFR-P, phosphorylated epidermal growth factor; HER2-P, phosphorylated human epidermal growth factor 2; HMGA2, high mobility group AT-hook 2; KLF12, krüppellike factor 12; MMTS1, metastasis suppressor 1; PIP2, phosphatidyl-inositol 4,5 biphosphate; PIP3, phosphatidyl-inositol 3,4,5 triphosphate; PI3K, phosphoinositide-3 kinase; PTEN, phosphatase and tensin homolog; PTPN12, tyrosine phosphatase non-receptor 12; RhoA, ras homolog A; SMAD4, suppressor of mothers against decapentaplegic 4; Sp1, transcription factor Sp1, XIAP, X-linked inhibitor of apoptosis.

an impact on cellular migration of EOC cell lines and acts as a scaffold protein that interacts with multiple partners to regulate actin dynamics $(41,42)$. In addition, suppression of MMTS1 has been shown to activate ras homology A (RhoA), a small GTPase, which promotes breast cancer metastasis (43). miR-182 is overexpressed in EOC compared to corresponding normal tissue (44). Data correlating its expression with clinical outcome are still pending.

$m i R-205$. miR-205 is up-regulated in EOC and its overexpression correlates with poor survival (45). miR-205 promotes EOC cell proliferation, migration and invasion as shown with HO-8910 and SKOV-3 cells as well as resistance against cisplatin. Suppressor of mothers against decaplentaplegic 4 (SMAD4) and phosphatase and tensin homolog (PTEN) have been identified as direct targets of miR205 in EOC cells (Figure 1) (45-47). Smad4 is a key regulator of transforming growth factor $\beta$ (TGF $\beta$ )-signaling. After TGF $\beta$ binds to its receptor, Smad4 forms a complex with $\mathrm{Smad} 2 / 3$ and translocates to the nucleus where it binds DNA and up-regulates the expression of target genes that cause cell-cycle arrest and apoptosis (46). PTEN is a key modulator of phosphoinositide3 kinase (PI3K/AKT) signaling by catalysing the conversion of membrane-bound second messenger phosphatidyl-inositol 3,4,5 triphosphate (PIP3) to PI 4,5 biphosphate (PIP2) (47). HO-8910 cells stably expressing miR-205 gave rise to increased number of nodules in omentum, peritoneum, bowel mesentery, liver and ovary in nude mice after i.p. injection in comparison to the control cell line (45).

$m i R-141$. In EOC cell lines and clinical samples the mean expression level of miR-149 is approximately 10-fold higher than that of human ovarian surface epithelium (HOSE) cell lines and normal ovarian tissues (48). In A2780, SKOV3 and OVCA433 cells, miR-141 augments anchorage-independent growth and survival (48). One of the direct targets of miR-141 that has been identified is Krüppel-like factor 12 (KLF12) (Figure 1) (48). KLF12 is a member of the KLF family of transcription factors which are involved in EMT, survival and development $(49,50)$. In EOC cells, KLF12 exerts a tumorsuppressive effect (48). KLF12 antagonizes transcription factor Sp1 which up-regulates survival factor survivin (51). Overexpression of miR-141 or loss of KLF12 enhances anoikis resistance by modulating the $\mathrm{Sp} 1 /$ survivin/ X-linked inhibitor of apoptosis (XIAP) intrinsic apoptotic pathway (48). In vivo studies were performed by injection of SKOV3 cells 


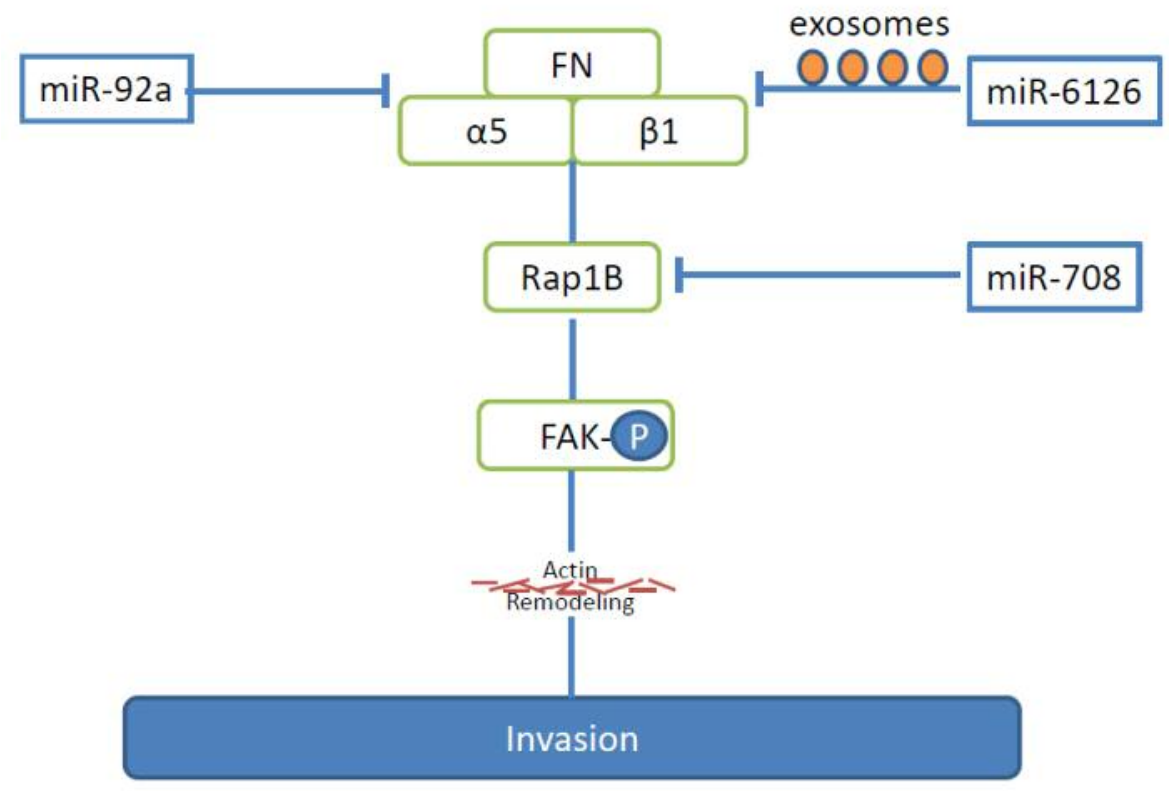

Figure 2. miRs -92a, -708 and -6126 inhibit integrin-related pathways of metastases in ovarian cancer. The pathways outlined lead to inhibition of $F A K$ and actin remodeling. a5, Alpha5, integrin subunit; b1, beta1, integrin subunit; FAK-P, phosphorylated fokal adhesion kinase; FN, fibronectin; Rap $1 B$, ras-related protein- $1 B$.

stably expressing miR-141 into nude mice. Significantly more nodules were observed across the peritoneal cavity with the transfected cell line (48). Increased survival, enhanced metastatic capability, or a combination of both might be responsible for the observed effects. Clinical data correlating expression of miR-141 with survival are not yet available.

\section{Other EOC Metastasis-promoting miRs not yet Validated in Preclinical In Vivo Models}

miR-194 is up-regulated in EOC compared to normal ovarian tissue and enhances proliferation, migration and invasion of SKOV3 and OVCAR3 cells (52). Protein tyrosine phosphatase non-receptor 12 (PTPN12) was identified as a direct target of miR-194 (Figure 1) (52). PTPN12 plays an important role in adhesion and motility in several types of cancer $(53,54)$. Due to loss of PTPN12 several tyrosine kinases are activated in breast cancer, including EGFR and human epidermal growth factor receptor 2 (HER2). PTPN12 suppresses growth and metastasis of PTPN12 deficient breast cancer cells and low PTPN12 correlates with poor prognosis and tumor recurrence in breast cancer patients (52).

miR-146a and miR-150 promote survival and spheroid formation as well as cisplatin resistance of EOC cells (55). Both of them exhibit significantly increased expression in omental metastases in comparison to the corresponding normal tissues (52). miR-196a is overexpressed in EOC compared to normal ovarian surface tissue and correlates with international federation of gynecology and obstetrics (FIGO)-stage, tumor size, lymph node metastases and high levels are associated with poor survival (56).

\section{Metastasis-suppressive miRs with In Vivo Activity in Preclinical Models}

$m i R-92 a$. Identification of miR-92a was catalysed by the finding that high integrin $\alpha 5$ expression is a predictor for reduced survival for patients with advanced EOC (57). Based on bioinformatic information, integrin $\alpha 5$ was identified as a direct target of miR-92a. Integrin $\alpha 5$ predominantly binds to integrin $\beta 1$ to form integrin $\alpha 5 \beta 1$, which recognizes the arginine-glycine-aspartate motif of its ligand fibronectin (FN), one of the most abundant proteins in the extracellular matrix (ECM) of the omentum and peritoneum (Figure 2) (58). miR-92a inhibits the adhesion to FN, invasion and proliferation of EOC cell lines SKOV3, A2780, OVISE and HeyA-8 (57). Mir-92 inhibits tyrosine phosphorylation of focal adhesion kinase (FAK) (59), a kinase involved in integrin signaling, and subsequently down-regulates matrix metalloprotease 2 (MMP2) (57). HeyA-8 EOC cancer cells stably transduced to express miR-92a, gave rise to reduced numbers of peritoneal metastases and tumor burden after i.p. injection into nude mice (57). However, the function of miR$92 \mathrm{a}$ in EOC is a controversial issue. An independent study suggests a down-regulation of miR-92a in EOC, linking it to tumorigenesis or progression of EOC (60). 


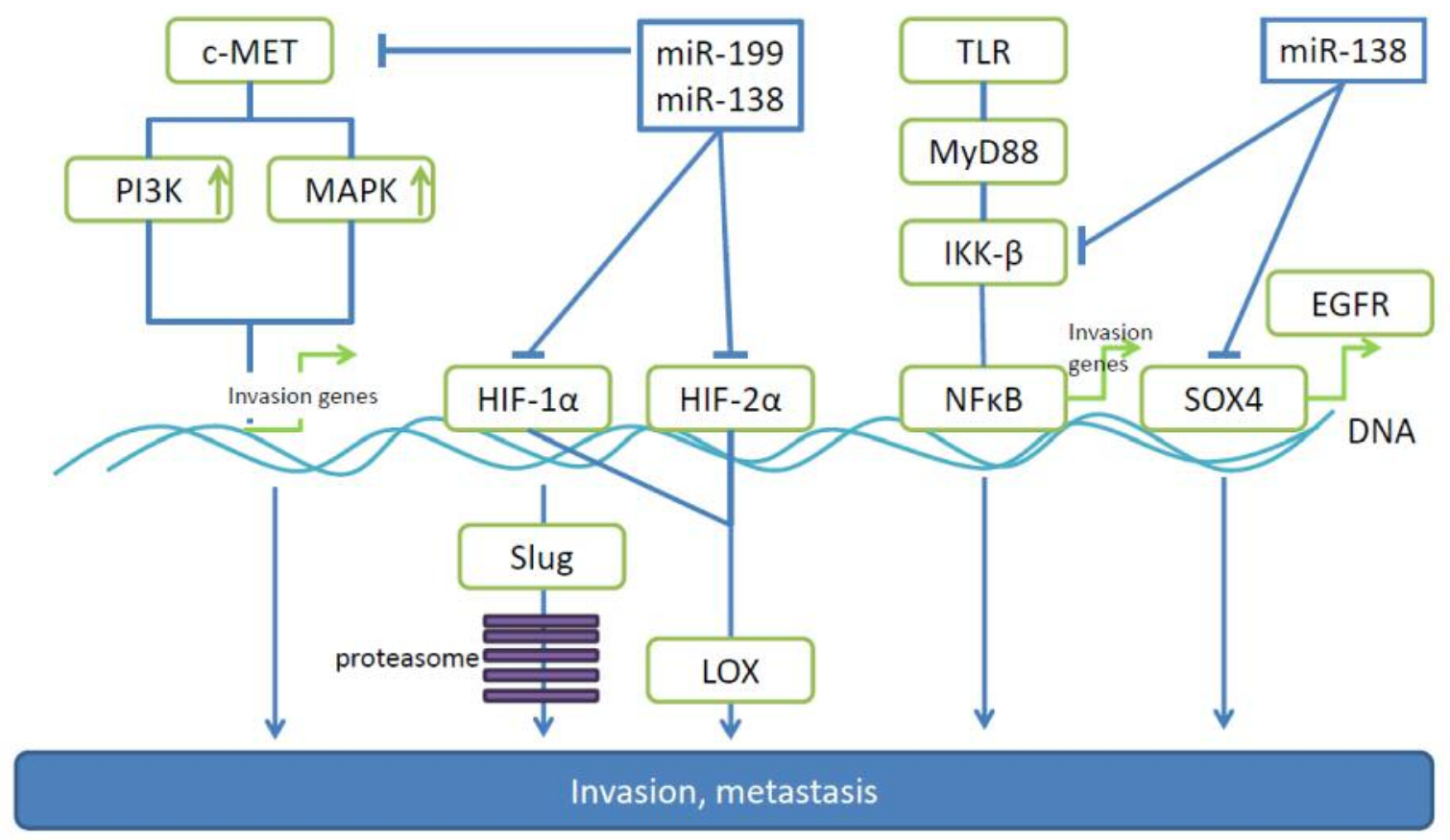

Figure 3. miRs -138 and -199 are down-regulated in ovarian cancer and target pro-metastatic genes. miR-138 and -199 related pathways leading to invasion and metastasis of ovarian carcinoma are shown. EGFR, Epidermal growth factor receptor; HIF-1 $\alpha$, hypoxia-inducible factor $1 \alpha$; HIF$2 \beta$, hypoxia-inducible factor $2 \beta$; IKK $\beta$, IK kinase $\beta$; LOX, lysyl-oxidase; MAPK, mitogen-activated protein kinase; MET, MET tyrosine receptor kinase; MyD88, myeloid differentiation factor 88; $N F \kappa B$, nuclear factor $\kappa B ; P I 3 K$, phosphoinosite-3-kinase; slug, transcription factor slug; SOX4, SRY-box4; TLR, toll-like receptor.

miR-6126. miR-6126 is secreted in exosomes by several EOC cell lines and targets integrin $\beta 1$ directly (Figure 2) (61). Integrin $\beta 1$ has been identified as a key mediator of EOC metastasis $(6,62,63)$. Ectopic expression of miR-6126 impairs invasion in HeyA8 and HeyA8-MDR EOC cells (61). Low integrin $\beta 1$ and high miR-6126 co-expression are correlated with longer survival in EOC patients (61). In vivo investigations of the role of miR-6126 were performed in the orthotopic HeyA8 EOC metastasis model. Tumor cells were inocculated (i.p.), followed by tail vein injection of liposomes carrying a miR-6126 mimetic. Tumor weight in the mimic-treated mice was significantly smaller than in the control miR group (61). Inhibition of tumor cell proliferation and angiogenesis as well as reduced integrin $\beta 1$ levels were observed in the xenografts. miR-6126 mimic treatment resulted in increased miR-6126 and decreased integrin $\beta 1$ levels in the exosomes (61).

miR-138. Making use of isogenic pairs of low and high invasive EOC cell lines, mir-138 was found to be downregulated in highly invasive cells (64). In vitro experiments have identified miR-138 as an inhibitor of migration and invasion based on targeting of SRY-related high mobility group box 4 (SOX4) and hypoxia-inducible factor $1 \alpha(\mathrm{HIF} 1 \alpha)$ (Figure 3) (64). Overexpression of SOX4 $(2,3)$ and HIF-1 $\alpha$
(4) reverse miR-138 mediated suppression of cell invasion. SOX4 activates pro-metastatic EGFR through trancriptional control (65-68) and HIF-1 $\alpha$ mediates proteosomal degradation of EMT-promoting transcription factor slug $(64,69)$. In vivo properties of miR-138 were evaluated in an orthotopic model after intrabursal injection of SKOV-16iv cells stably expressing miR-138 and a corresponding control cell line. No effect on primary tumor weight was noted, however, lower incidence of peritoneal metastases and ascites formation was observed with the transfected cell line (64). In patient derived EOC cells, miR-138 low/SOX4 high expression correlates with lymph node metastases, higher tumor grade and larger ascites volume (64).

$m i R-199$. miR-199 is down-regulated in the majority of EOCs and has been shown to directly target pro-metastatic proteins such as c-MET, HIF- $1 \alpha, \mathrm{HIF}-2 \beta$ and Ik kinase $\beta$ IKK $\beta$ in this tumor entity (Figure 3) (70-72). In EOC cell lines, miR199 inhibits proliferation, invasion and adhesion as well as extracellular signal regulated kinase and nuclear factor $\mathrm{kB}(\mathrm{NFKB})$ signaling (70-72). Inhibition of HIF levels, down-regulates lysyl-oxidase (LOX), a matrix remodeling enzyme which cross-links collagens (73). c-MET is a wellvalidated target for anti-metastatic therapy in $\operatorname{OVC}(74,75)$. 


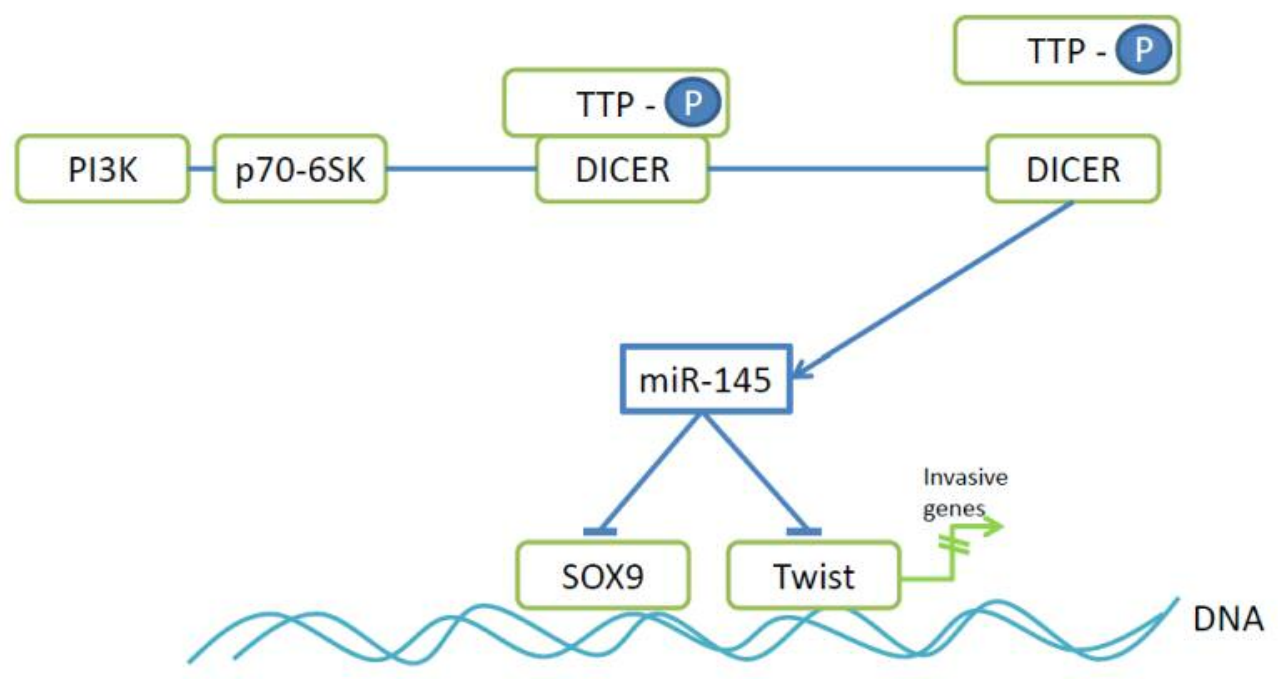

Figure 4. Mode of action of anti-metastatic miR-145. P70-6SK phosphorylates TTP leading to dissociation of the TTP-DICER complex resulting in processing and activation of miR-145 by DICER. DICER, Microprocessor complex; PI3K, phosphoinosite 3-kinase; p70-S6K, p70 S6 kinase; SOX9, SRY-box 9; TTP-P, phosphorylated tristetraprolin; Twist, transcription factor Twist.

IKK $\beta$ promotes function of the toll-like receptor-myeloid differentiation factor-NFkB (TLR-MyD88-NFkB) pathway, which enhances the inflammatory microenvironment, a prerequisite for EOC progression and dissemination $(72,76-$ 78). This function of IKK $\beta$ is based on inhibition of inhibitor of NFKB (IKB), by promoting its degradation through the proteasome and inhibiting the nuclear translocation of NFkB (76). In vivo, miR-199 inhibits growth and peritoneal seeding of ovarian tumors after i.p. injection of SKOV3 and A2780 cells $(70,71)$. In these models total tumor burden and number of metastases on the peritoneal surface, omentum, small bowel mesentery and both ovaries were reduced. Clinical data correlating miR-199 levels with prognosis and overall survival are not yet available.

miR-145. miR-145 has the capacity to suppress multicellular spheroid (MCS) formation of ovarian cancer cells by preventing the up-regulation of $\mathrm{N}$-cadherin expression $(79,80)$. N-cadherin expression is regulated by Twist and SOX9 and both have been identifed as direct targets of miR145 (79). Twist is an EMT-promoting transcription factor and its expression correlates with bad prognosis in ovarian cancer patients (81), whereas transcription factor SOX9 promotes pro-tumoral and metastatic signaling in ovarian cancer cells (82). miR-145 belongs to a subset of miRs whose expression is promoted by the interaction of microprocessor DICER (83) and zinc finger protein tristetraprolin (TTP) (Figure 4) (84). p70 S6 kinase (p70-S6K), a downstream effector of PI3K signaling (85) and frequently constitutively active in EOC disrupts this interaction by phosphorylating TTP and thus down-regulating expression of miR-145 (79). Metaanalysis in the Oncomine database has indicated that high levels of p70-S6K and low TTP levels are associated with ovarian cancer progression (79). In vivo anti-metastatic activity of miR-145 was shown in nude mice after i.p. injection of SKOV3 cells stably transduced with miR-145. The number and size of tumor nodules in the peritoneal cavity as well as the volume of ascites fluid were reduced with transfectants in comparison to the control cell line (79).

$m i R-708$. miR-708 is induced by glucocorticoids (GC) in EOC cells (86). GC are used in conjunction with chemotherapy of EOC to prevent hypersensitivity reactions (87). miR-708 is down-regulated in metastatic OVC and patients with high miR-708 expression show significantly better survival (86). miR-708 inhibits migration and invasion of EOC cell lines as shown by wound healing and transwell Boyden chamber assays (86). Ras-related protein-1B (Rap-1B), a small GTPase, was identified as a direct target of miR-708 (Figure 2) (86). Rap-1B facilitates integrin-mediated signaling and actin remodeling via FAK and paxillin and stimulates EOC cell invasion and metastasis $(88,89)$. miR-708 or depletion of Rap-1B decreases adhesion of EOC cells to FN and collagen type I, reduces number and density of focal adhesions and rescues miR-708 suppressed cell growth and invasion (86). miR-708 transfectants of SKOV-I6iv cells gave rise to reduced lung metastatic activity after tail vein injection and orthotopic injection into the mouse ovarian bursa and significantly reduced abdominal metastasis with transfectants in comparison to the control cell line as shown by 
bioluminescence imaging (86). GCs also suppress metastasis of SKOV-I6iv cells in the orthotopic model described above.

miR-26b. miR-26 is down-regulated in EOC and low expression is associated with FIGO stage, poor disease free survival, higher risk of distant metastases, recurrence and overall survival (90). Karyopherin $\alpha 2$ (KPNA2) was identified as one of its targets (90). KPNA2 is a nuclear transport protein (91) and its down-regulation promotes expression of stem cell pluripotency homeobox transcription factor 4 (OCT4) $(90,92$, 93). Overexpression of KPNA2 in EOC correlates with poor prognosis (94). An inverse correlation between KPNA2 and miR-26a expression in EOC has been observed (90). The miR26/KPNA2/OCT4 axis inhibits EOC proliferation, migration and sphere-forming ability in vitro and in vivo (90). Ectopic expression of miR-26b down-regulates OCT4 and vimentin levels and up-regulates E-cadherin expression (90). However, overexpression of KPNA2 could not completely counteract the effect of miR-26b indicating involvement of additional targets (90). In vivo experiments were performed with OVCAR3 cells stably expressing miR-26b. Tumor growth was inhibited in the transfectant cell line in comparison to mice injected with the control cell line after injection into the dorsal flank. Tail vein injection experiments resulted in fewer and smaller micrometastases in the lungs with the transfectant cell line.

$m i R-448$. miR-448 inhibits proliferation and invasion of SKOV3 and A2780 EOC cell lines and is down-regulated in human EOC (95). CXC chemokine ligand 12 (CXCL12) was identified as one of the direct targets of miR-448 (Figure 5) (95). CXCL12 is a chemokine that mediates interaction of tumor cells with the microenvironment, angiogenesis, tumor progression and metastasis $(96,97)$. miR-448 inhibits proliferation, migration and invasion of SKOV3 and A2780 cells in vitro (95). miR-448 transfected SKOV3 cells exhibited suppressed cell growth in nude mice in comparison to the control cell line. Additional studies are need to investigate the in vivo anti-metastatic activity of miR-448. miR-448 is down-regulated in human EOC (95), further correlations with clinical parameters are not yet available.

$m i R-214$. miR-214 was identified as an important mediator of the tumor- and metastasis-promoting role of cancer-associated fibroblasts (CAFs) in EOC (98). miR-214 (99) was downregulated in normal human ovarian fibroblasts during coculturing with HeyA8 EOC cells resulting in their conversion to CAFs (98). The induced CAFs promoted enhanced invasiveness of HeyA8 cells. CAFs increased growth and invasion of co-injected HeyA8 cells and replaced normal ovarian structures such as follicles or fallopian tubes in an orthotopic mouse model of EOC (98). It was shown that miR214 acts on CC chemokine ligand 5 (CCL5) mRNA as a direct

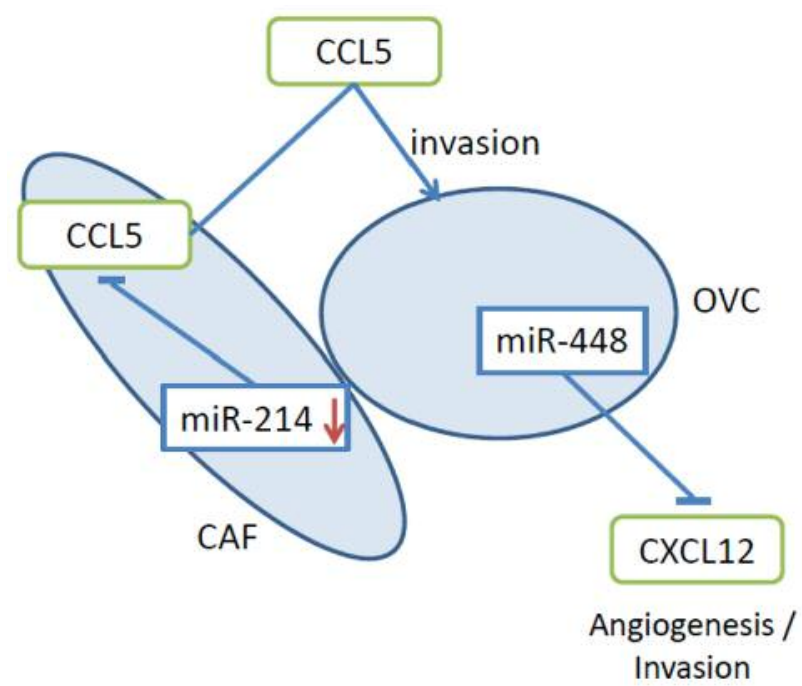

Figure 5. miR-s -214 and -448 inhibit chemokines mediating angiogenesis and invasion of ovarian carcinoma cells. miR-448 inhibits CXCL12. miR-214 down-regulates CCL5 and is decreased in CAFs after their interaction with ovarian cancer cells. CAF, Cancerassociated fibroblast; CCL5, CC chemokine ligand 5, CXCL 12, CXC chemokine ligand 12 .

target and that the in vivo effects could be blocked by an antibody directed against CCL5 (Figure 5) (98). In EOC, CCL5 levels correlate with tumor progression (100). Similar observations in breast cancer cells were reported earlier (101). Overexpression of CCL5 in fibroblasts was sufficient to promote metastasis of admixed with breast cancer cells (101).

miR-373. miR-373 is down-regulated in EOC and its expression levels inversely correlate with clinical stage and histopathological grade of EOC (102). In cells transfected with miR-373 EMT is inhibited and in vitro invasion of SKOV3 is mitigated (102). In vivo, i.p. injected miR-373expressing SKOV-3 cells gave rise to fewer metastases in the peritoneal cavity, peritoneal wall, small intestine, colon, stomach, liver and diagraphm (102). Rab22 was identified as a direct target of miR-373 (Figure 6) (102). Rab22 is a small GTPase and member of the Rab family proteins which are involved in the endocytic pathway (103). Rab22 activates Rab5 which is functionally involved in degradation of EGFR and plays a key role in migration of cancer cells through the integrin-mediated pathway (104-106). There is evidence that miR-373 may suppress TGF $\beta$ signaling through the Rab22Rab5 pathway (107).

miR-193b. Studies addressing the interaction between EOC cells and a 3D culture model which mimics human omentum revealed the down-regulation of miR-193 in tumor cells after 


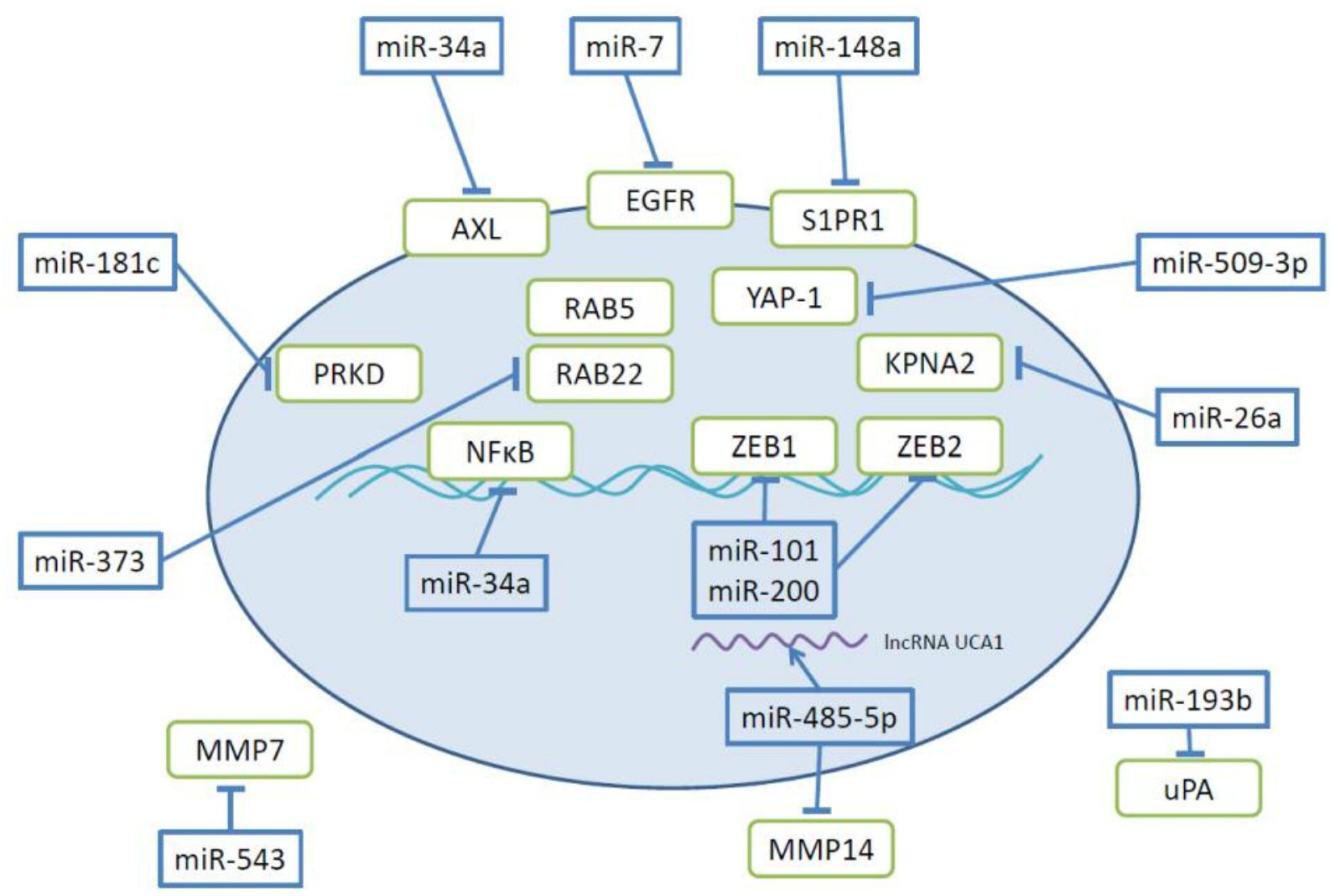

Figure 6. Further miRs and their targets involved in modulation of invasion and metastasis of ovarian cancer. The oval circle represents an ovarian carcinoma cell. AXL, Transmembrane tyrosine kinase AXL; EGFR, epidermal growth factor receptor; KPNA2, karyopherin; lncRNA, long non-coding RNA; MMP 7,14, matrix metalloproteinase 7, 14; NFkB, nuclear factor $k B$; PRKD, protein kinase C delta; RAB 5,22, RAB family GTPase 5,22, SIPR1, shingosine-1-phosphate-receptor; UCA-1, urothelial cancer associated-1; uPA, urokinase plasminogen activator; YAP, yes-associated protein.

interaction of both components (108, 109). DNA methyltransferase 1 (DNMT1) was found to be responsible for methylation of the miR-193b promoter (108). miR-193b impairs colony formation and invasion through 3D cultures in Hey8 cells (108). Human urokinase plasminogen activator (uPA) was identified as a direct target of miR-193b (Figure 6). The effects observed are at least partly due to inhibition of uPA, because blocking of uPA mimics most of the effects of miR-193b (108). UPA is a well validated target as a mediator of invasion and metastasis (110-113). Hey8 cells transfected with miR-193b gave rise to a $50 \%$ decrease of tumor burden after i.p. injection in comparison to the control cell line (108). Data connecting miR-193b to clinical parameters are not yet available.

$m i R-200$. miR-200 is a family of miRs with a high degree of sequence homology with only one nucleotide difference in their seed sequence. The family is composed of miR-200a, 200b, -200c, miR-141 and miR-429 (114). Due to the homology in the seed sequences they share many targets. Inhibition of EMT seems to be a shared property of the miR200 family. Investigations with the 60 NCI cell line panel and additional studies have identified transcription factors zinc E-box binding homeobox 1 and 2 (ZEB1 and ZEB2) as direct target of miR-200 (115,116,117). Zn-finger transcription factors ZEB1 and ZEB2 bind to the E-box of the E-cadherin promoter and inhibit its expression. Ectopic expression of miR-200 mediates up-regulation of E-cadherin and reduces motility of the corresponding cell lines (115). For EOC inconsistent correlations between expression of miR-200 and disease progression has been reported (114, $118,119)$. One of the reasons for these discrepancies is the use of varying types of normal cells in the profiling studies ranging from whole ovary (ovarian surface epithelium only $1 \%$ of the cells), to immortalized ovarian surface epithelial cells and primary cultures of human cells from the surface of normal ovaries $(114,118,119)$. Another complicating issue might be the dynamic variation of miR-200 expression during disease progression $(118,120)$. A current model suggests high miR-220, low ZEB1+2 and high E-cadherin expression in primary ovarian carcinoma and low miR-200, high ZEB1+2 expression in ascites and metastatic EOC (118, 
120). Anti-metastatic function of miR-200c was demonstrated in vivo with $\mathrm{CD} 117^{+}, \mathrm{CD} 44^{+} \mathrm{CSC}$ isolated from SKOV3 cells (121). Overexpression of miR-220c in these cells leads to inhibition of EMT, CSC growth and lung metastases after s.c. injection (121). It is notworthy to mention that pro- and anti-metastatic functions have been described for miR-200 $(122,123)$. Further studies are needed to resolve the function of miR-200s in EOC.

\section{Other EOC-related Metastasis-suppressing miRs}

In this chapter we describe EOC metastasis-related miRs with promising preclinical in vitro data and a varying degree of clinical validation and pending validation in preclinical in vivo models. They are involved in regulation of diverse pathways, transcription factors and regulation of MMPs.

miR-7 and miR-34a target transmembrane receptor tyrosine kinases EGFR and AXL (Figure 6). miR-7 inhibits EGFR, a driver of EOC cell migration and proliferation (124, 125). Investigation of miR-7 expression in 17 paired EOC versus normal tissues inversely correlates miR-7 levels and EOC metastasis. In HO-890 and ES2 EOC cells transfected with miR-7, invasion and migration was suppressed in vitro as well as AKT/ERK1/2 pathway activation in an EGFRdependent manner (126). miR-7 was shown to be downregulated in the highly metastatic EOC clone HO-8910pm in comparison to the original cell line HO-8910. miR-34a inhibits AXL as a direct target (127). AXL mediates proliferation-, invasion- and angiogenesis-related functions in cancer (128). Overexpression of miR-34a in HO-890 and SKOV3 EOC cells resulted in inhibition of proliferation, invasion and migration, and in addition decreased expression of $\mathrm{N}$-cadherin and up-regulation of E-cadherin (127). miR$34 \mathrm{a}$ is down-regulated in EOC compared with adjacent nonneoplastic tissue.

miR-340 has been identified to directly target NFkB1 in EOV (129). NFKB1 is a homodimer of p50 and regulates cell-cycle, apoptosis, immune responses and tumorigenesis $(130,131)$. Decreased levels of miR-340 were noted in the EOC cell lines OVCAR3, SKOV3, HO-8910 and ES2 in comparison to FTE 187 cells derived from normal human immortalized fallopian tube (129). miR-340 restrains proliferation by impeding $G_{1} / S$ transition and inhibits invasion by down-regulation of MMP2, MMP9, N-cadherin, vimentin and up-regulation of E-cadherin (129). Data for EOC specimens are not yet available.

Sphingosine-1-phosphate-receptor (S1PR) was identified as a direct target of miR-148a (Figure 6) (132). S1P/S1PR signaling has been shown to play a role in a number of cellular functions including cell growth, migration and invasion and inhibiting EOC invasion potential $(133,134)$. Expression of miR-148 is reduced in SKOV3, OVCAR and A2780 EOC cells in comparison to normal ovarian tissue- derived cell line HUM-CELL-0088 (132). miR-148a expression is also reduced in EOC in comparison to normal ovarian tissues (135).

Protein kinase $\mathrm{C}$ delta $(\mathrm{PKCD})$ has been identified as a direct target of miR-181c (Figure 6) (136). PKCD is involved in pro- and anti-tumoral functions depending on the tumor type (137). miR-181 inhibits proliferation and invasion of A2780 cells and is down-regulated in EOC tissues in comparison to normal tissues (136).

Yes-associated protein (YAP) $(138,139)$, an effector of the Hippo pathway, was identified as a direct target of miR-509$3 p$ (Figure 6) (140). miR-509-3p attenuates migration and disrupts multi-cellular spheroids in HEY8, OVCAR3,4,8 and SKOV3 cells (140). miR-509-3p is more abundant in patients with favorable prognosis. Its target, YAP1, is functionally associated with the ECM through its non-canonical Hippoindependant role as a mechanotransducer. YAP1influences how tumor cells sense and respond to the mechanical properties of the ECM and their microenvironment and thus impacts cell proliferation, differentiation, migration and migration (141-143).

miR-101 directly targets transcription factors ZEB1 and ZEB2, inhibiting EMT, invasion and migration of SKOV3 cells (144). miR-543 and miR-485-5p are involved in MMP-related interactions. miR-543 inhibits translation of MMP7 by binding to its 3'-UTR (22). In EOC, placental growth factor (PlGF) mediates decrease in miR-543 (145). MMP-7 is an important mediator of invasion of EOC cells due to its induction by mesothelin $(146,147)$. miR-485-5p targets MMP14 and is neutralized by binding to lncRNA urothelial cancer associated 1 (UCA-1) acting as a sponge (Figure 6) (148).

\section{Therapeutic Aspects, Key Issues and Expert Commentary}

We have analysed the steady-state levels of selected miRs in ovarian cancer specimen by summarizing data as derived from TCGA (Figure 7). Notworthy, the poor expression of miRs-26b, -138, -193b, -199, -373, -448, and -708 correlates with their anti-metastatic potential. Furthermore, significant expression of miRs-145, -200a, -200b and -205 correlates with their metastatic propensity. We have outlined in vitro and in vivo target-validation related experiments for miRs involved in metastasis of EOC in the previous sections. miRs target the mRNAs derived from several genes and corresponding pathways which may translate into enhanced efficacy compared to monotarget based intervention, however this may also result in increased toxicity (149). The mode of therapeutic intervention and corresponding agents are driven by their metastasispromoting or suppressive properties $(27,28,150,151)$. This issue has been discussed in the context specific miRs in previous chapters of this review and therefore only the key features of therapeutic intervention with miRs will be summarized here. 


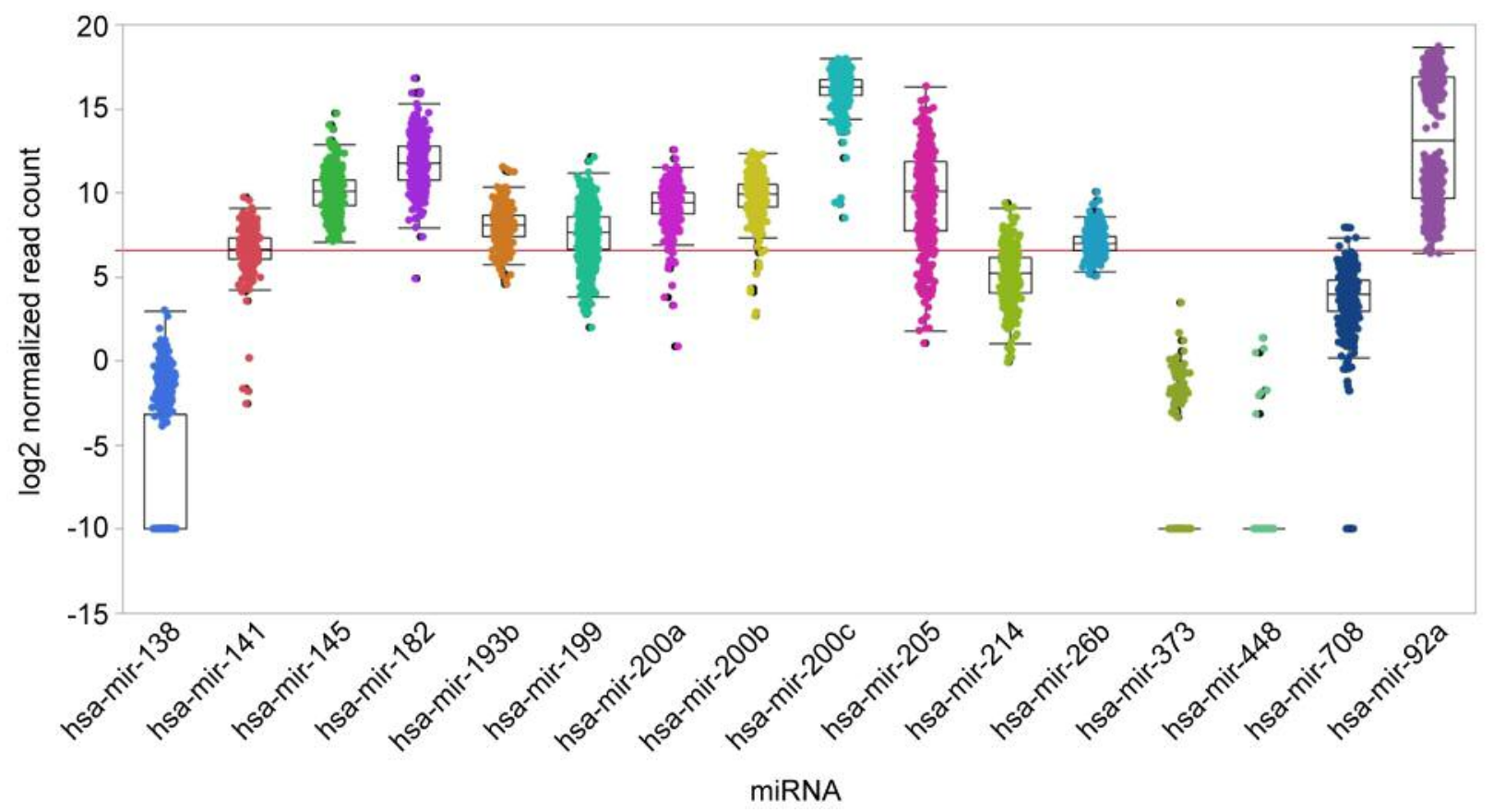

Figure 7. Steady-state levels of selected miRs in ovarian cancer. Log2 normalized expression counts as derived by small RNA sequencing from the ovarian carcinoma cohort from TCGA are displayed. This cohort comprises data from 453 tumor patients. No matched normal samples are provided. The red line indicates a count of 100 normalized reads and separates very low from higher expression levels. Data are shown as box plots.

Metastasis-promoting miRs can be inhibited by single-stranded miRs based on first generation antisense oligonucleotides (ASO) or locked nucleic acids (LNA) with complementary sequences to the miRs to be inhibited $(27,28,150,151)$. For improvement of the pharmco-kinetic (PK) and pharmacodynamic (PD) properties, diverse modifications of the nucleotide backbone have been introduced. They also can be inhibited by miR sponges containing reiterated tandem repeats of the target sequence or by masking of the miR-binding site of the target mRNA by making use of single-stranded RNA complementary to the target sequence $(150,152)$. Tumor-suppressing miRs can be reconstituted by gene therapy or by miR mimetics (synthetic double-stranded RNAs) matching to the corresponding miR sequence. Despite significant progress in delivery techniques, making use of viral vectors, coated and uncoated liposomes, nanoparticles and carrier-related compounds such as polyethylene glycole, synthetic polyethylenimine, cyclodextran, $\mathrm{N}$-acetylgalactosamine and dendrimers, several critical issues remain to be resolved. Key challenges are targeting miRs to the disease site, tumor penetration, effective dose to reach the appropriate target cells, efficacy of endosomal escape, immunomodulatory off-target effects, toxicty related issues such as liver toxicity, cytokine-release syndrome and a number of additional issues $(27,28,150,151)$.

EOC might be a target-indication for miR-based therapy because some of these issues may be by-passed (153). EOC arises at the surface of the ovary, disseminates into the peritoneum and is therefore amenable to i.p. administration of therapeutic agents after debulking of the tumor mass. I.p. injection of the paclitaxel or cisplatin-based standard therapeutic regimen has been shown to improve the clinical outcome of patients after debulking of the tumor in comparison to i.v. injection due to increased drug concentration at the site of disease (154, 155). Antimetastatic activity of selected miRs after i.p. administration in several orthotopic EOC models has been described in previous chapters of this review. Also it is expected that i.p. administration of miR-related therapeutic agents will decrease systemic toxicity and to mediate vasculatureindependent exposure in clinical settings.

Targeting of miR-122 for treatment of Hepatitis C Virus (HCV) infection has proceeded to Phase II clinical studies (Roche/Santaris and Regulon Therapeutics) and is the most advanced miR-related approach (28). A Phase I study with miR-34 mimetic MRX 34 (Mirna Therapeutics) in patients with solid tumors was recently terminated due to side effects caused by cytokine-release syndrome. Clinical studies of miR-related agents in EOC are expected in the near future.

Taken together, prioritization of miR-related targets for treatment of dissemination of EOC should be based on the synoptic view of preclinical target validation data and the role of the corresponding miR in disease progression. From 
a technical point of view, i.p. delivery of miR-related therapeutic agents is a potential advantage versus i.p. delivery. Inhibition of overexpressed $\mathrm{miR}$ is a more promising approach than reconstitution of expression of down-regulated miRs. The present repertoire of targets for treatment of EOC (156) will be extended by miRs.

\section{References}

1 American Cancer Society. Facts and Figures 2016: Atlanta GA.: American Cancer Society, 2016.

2 Lengyel E: Ovarian Cancer development and metastasis. Am J Pathol 177: 1053-1064, 2010.

3 Agarwal R and Kaye SB: Ovarian cancer: strategies for overcoming resistance to chemotherapy. Nat Rev Cancer 3: 502-516, 2003.

4 Garcia A and Singh H: Bevacizumab and cancer. Ther Adv Med Oncol 5: 133-141, 2013.

5 Lopez J, Banerjee S and Kaye SB: New development in treatment of ovarian cancer - future perspectives. Annal Oncol 24(Suppl 10): 69-76, 2013.

6 Weidle UH, Birzele F, Kollmorgen G and Rueger R: Mechanisms and targets involved in dissemination of ovarian cancer. Cancer Genomics Proteomics 13: 407-423, 2016.

7 Brown JS, Kaye SB and Yap TA: PARP inhibitors: the race is on. Br J Cancer 114: 713-715, 2016.

8 Cannistra SA: Cancer of the ovary: N Engl J Med 351: $2519-$ 2529, 2004.

9 Tan DS, Agarwal K and Kaye SB: Mechanisms of transcoelomic metastases in ovarian cancer. Lancet Oncol 7: 925-934, 2006.

10 Abrahams VM, Straszewski SL, Kamsteeg M, Hanczaruk B, Schwartz PE, Rutherford TJ and Mor G: Epithelial ovarian cancer cells secrete functional Fas ligand. Cancer Res 63: 55735581, 2003.

11 Xu L, Yoneda Y, Herrera C, Wood J, Killion JJ and Fidler IJ: Inhibition of malignant ascites and growth of human ovarian carcinoma by oral administration of a potent inhibitor of the vascular endothelial growth factor tyrosine kinases. Int J Oncol 16: 445-454, 2000.

12 Strobel T and Cannistra SA: Beta1-integrins partly mediate binding by ovarian cancer cells to peritoneal mesothelium in vitro. Gynecol Oncol 73: 362-367, 1999.

13 Slack-Davies JK, Atkins KA, Harrer C, Hershey ED and Conaway M: Vascular cell adhesion molecule-1 is a regulator of ovarian cancer peritoneal metastasis. Cancer Res 69: 14691476, 2009.

14 Strobel T, Swanson L and Cannistra SA: In vivo inhibition of CD44 limits intra-abdominal spread of a human ovarian cancer xenograft in nude mice: a novel role for CD44 in the process of peritoneal implantation. Cancer Res 57: 1228-1232, 1997.

$15 \mathrm{Hu}$ L, Hofmann J, Holash J, Yancopoulos GD, Sood AK and Jaffe RB: Vascular endothelial growth factor trap combined with paclitaxel strikingly inhibits tumor and ascites, prolinging survival in a human ovarian cancer model. Clin Cancer Res 11: 6966-6971, 2005.

16 Nieman KM, Romero RL, Van Houten B and Lengyel E: Adipose tissue and adipocytes support tumorigenesis and metastasis. Biochim Biophys Acta 1831: 1533-1541, 2013.
17 Bapat SA, Mali AM, Koppikar CB and Kurrey NK: Stem and progenitor-like cells contribute to the aggressive behaviour of human epithelial ovarian cancer. Cancer Res 65: 3025-3029, 2005.

18 Kwon MJ and Shin YK: Regulation of ovarian cancer stem cells or tumor-initiating cells. Int J Mol Sci 14: 6624-6648, 2013.

19 Wang Y, Kim S and Kim IM: Regulation of metastasis by microRNAs in ovarian cancer. Front Oncol 4: 143, 2014.

20 Bartel DP: MicroRNAs: genomics, biogenesis, mechanism and function. Cell 116: 281-297, 2004.

21 Pillai RS: MicroRNA function: multiple mechansisms for a tiny RNA. RNA 11: 1753-1761, 2005.

22 Lin S and Gregory RI: MicroRNA biogenesis pathway in cancer. Nat Rev Cancer 15: 321-333, 2015.

23 Bertoli G, Cava C and Castiglioni I: MicroRNAs: New biomarkers for diagnosis, prognosis, therapy prediction and therapeutic tools for breast cancer. Theranostics 5: 1122-1143, 2015.

24 Bentwich I, Avniel A, Karov Y, Aharonov R, Gilad S, Barad O, Barzilai A, Einat P, Einav U, Merre E, Sharon E, Spector Y and Bentwich Z: Identification of hundreds of conserved and nonconserved human microRNAs. Nat Genet 37: 766-770, 2005.

25 Denli AM, Tops BB, Plasterk RH, Ketting RF and Hannon GJ: Processing of primary microRNAs by the microprocessor complex. Nature 432: 231-235, 2004.

26 Yi R, Qin Y, Macara IG and Cullen BR: Exportin-5 mediates the nuclear export of pre-microRNAs and short hairpin RNAs. Genes Dev 17: 3011-3016, 2003.

$27 \mathrm{Li} \mathrm{Z}$ and Rana TM: Therapeutic targeting of microRNAs: current status and future challenges. Nat Rev Drug Discov 13: 622-638, 2014.

28 Rupaimoole $\mathrm{R}$ and Slack FJ: Therapeutic challenges of microRNAs: current status and future challenges. Nat Rev Drug Discov 16: 203-222, 2017.

29 Westholm JO and Lai EC: Mirtrons: microRNA biogenesis via splicing. Biochimie 93: 1897-1904, 2011.

30 Garzon R, Marucci G and Croce CM: Targeting microRNAs in cancer: rationale, strategies and challenges. Nat Rev Drug Discov 9: 775-789, 2010.

31 Croce CM: Causes and consequences of microRNA dysregulation in cancer. Nat Rev Genet 10: 704-714, 2009.

32 Garzon R, Calin GA and Croce CM: MicroRNAs in cancer. Ann Rev Med 60: 167-179, 2009.

33 Calin GA, Dumitru CD, Shimizu M, Bichi R, Zupo S, Noch E, Alder H, Rattan S, Keating M, Rai K, Rassenti L, Kipps T, Negrini M, Bullrich F and Croce CM: Frequent deletions and down-regulation of micro-RNA genes miR15 and miR16 at $13 q 14$ in chronic lymphocytoc leukemia. Proc Natl Acad Scie USA 99: 15524-15529, 2002.

34 Calin GA, Cimmino A, Fabbri M, Ferracin M, Wojcik SE, Shimizu M, Taccioli C, Zanesi M, Garzon R, Aqeilan RI, Alder H, Volinia S, Rassenti L, Liu X, Liu CG, Kipps TJ, Negrini M and Croce CM: MiR-15a and miR-16-1 cluster functions in human leukemia. Proc Natl Acad Sci USA 105: 5166-5171, 2008.

35 Klein U, Lia M, Crespo M, Siegel R, Shen Q, Mo T, AmbesiImpiombato A, Califano A, Migliazza A, Bhagat $\mathrm{G}$ and DallaFavera R: The DLEU2/miR-15a/16.1 cluster controls B cell proliferation and ist deletion leads to chronic lymphocytic leukemia. Cancer Cell 17: 28-40, 2010. 
36 Kinose Y, Sawada K, Nakamura K and Kimura T: The role of microRNAs in ovarian cancer. Biomed Res Inst 2014: 249393, 2014.

37 Zaman MS, Maher DM, Khan S, Jaggi M and Chauhan SC: Current status and implications of microRNAs in ovarian cancer diagnosis and therapy. J Ovarian Res 5: 44, 2012.

38 Xu X, Ayub B, Liu Z, Serna VA, Qiang W, Liu Y, Hernando E, Zabludoff S, Kunta T, Kong B and Wei JJ: Anti-miR182 reduces ovarian cancer burden, invasion and metastasis: an in vivo study in orthotopic xenografts of nude mice. Mol Cancer Ther 13: 1729-1739, 2014.

39 Liu Z, Liu J, Segura MF, Shao C, Lee P, Gong Y, Hernando E and Wie JJ: miR-182 overexpression in tumorigenesis of high grade serous ovarian carcinoma. J Pathol 228: 204-215, 2012.

$40 \mathrm{Wu} \mathrm{J}$ and Wie JJ: HMGA2 and high-grade serous ovarian carcinoma. J Mol Med 91: 1155-1165, 2013.

41 Xie F, Ye L, Ta M, Zhang L and Jiang WG: MTSS1, a multifunctional protein and ist role in cancer invasion and metastasis. Front Biosci 3: 621-631, 2011.

42 Liu R, Martin TA, Jordan NJ, Ruge F, Ye L and Jiang WG: Metastasis suppressor 1 expression in human ovarian cancer: the impact on cellular migration and metastasis. Int J Oncol 47: 1429-1439, 2015.

43 Lei R, Tang J, Zhuang X, Deng R, Li G, Yu J, Liang Y, Xiao J, Wang HY, Yang Q and Hu G: Suppression of MIM by microRNA-182 activates RhoA amd promotes breast cancer metastasis. Oncogene 33: 1287-1296, 2014.

44 McMillen BD, Aponte MM, Liu Z, Helenowski IB, Scholtens DM, Buttin BM and Wei JJ: Expression analysis of miR-182 and its associated target genes in advanced ovarian carcinoma. Mod Pathol 25: 1644-1653, 2012.

45 Li Y, Hu K, Gong G, Zhu D, Wang Y, Liu H and Wu X: Upregulation of miR-205 transcriptionally suppresses SMAD4 and PTEN and contributes to human ovarian cancer suppression. Sci Rep 7: 41330, 2017.

46 Yang G and Yang X: Smad4-mediated TGF-beta signaling in tumorigenesis. Int J Biol Sci 6: 1-8, 2010.

47 Song MS, Salmena L and Pandolfi PP: The function and regulation of the PTEN tumor suppressor. Nat Rev Mol Cell Biol 13: 283-296, 2012.

48 Mak CS, Yung MM, Hui LM, Leung LL, Liang R, Chen K, Liu SS, Qin Y, Leung TH, Lee KF, Chan KK, Ngan HY and Chan DW: microRNA-141 enhances anoikis resistance in metastatic progression of ovarian cancer through targeting KLF12/Sp1/ survivin axis. Mol Cancer 16: 11, 2017.

49 Limame R, de Beeck KO, Van Laere S, Croes L, De Wilde A, Dirix L, Van Camp G, Peeters M, De Wever O, Lardon F and Pauwels P: Expression profiling of migrated and invaded breast cancer cells predicts early metastatic relapse and reveals Krüppel-like factor 9 as a potential suppressor of invasive growth in breast cancer. Oncoscience 1: 69-81, 2013.

50 Godin-Heymann N, Brabetz S, Murillo MM, Saponaro M, Santos CR, Lobley A, East P, Chakravarty P, Matthews N, Kelly G, Jordan S, Castellano E and Downward J: Tumorsuppression function of KLF12 through regulation of anoikis. Oncogene 35: 3324-3334, 2016.

51 Chen X, Duan N, Zhang C and Zhang W: Survivin and tumorigenesis: molecular mechanisms and therapeutic strategies. J Cancer 10: 314-323, 2016.
52 Liang T, Li L, Cheng Y, Ren C and Zhang G: MicroRNA-194 promotes the growth, migration, and invasion of ovarian carcinoma cells by targeting protein tyrosine phosphatase nonreceptor type 12. Onco Targets Ther 9: 4307, 2016.

53 Streit S, Ruhe JE, Kynazev P, Kynazeva T, Iacobelli S, Peter S, Hoefler $\mathrm{H}$ and Ullrich A: PTP-PEST phosphatase variations in human cancer. Cancer Genet Cytogenetics 170: 48-53, 2006.

54 Zheng Y, Yang W, Xia X, Hawke D, Liu DX and Lu Z: Rasinduced and extracellular signal-regulated kinase 1 and 2 phosphorylation-dependent isomerization of tyrosine phosphatase (PTP)-PEST by PIN1 promotes FAK dephosphorylation by PTPPEST. Mol Cell Biol 31: 4258-4269, 2011.

55 Sun T, Aceto N, Kessler JD, Zhou C, Migliaccio I, Nguyen DX, Pavlova NN, Botero M, Huang Y, Bernardi RI, Schmitt E, Hu G, Li MZ, Dephoure N, Gygi SP, Rao M, Creighton CJ, Hilsenbeck SG, Shaw CA, Muzny D, Gibbs RA, Wheeler DA, Osborne CK, Schiff R, Bentires-Alj M, Elledge SJ and Westbrook TF: Activation of multiple proto-oncogenic tyrosine kinases in breast cancer via loss of the PTPN12 phosphatase. Cell 144: 703-718, 2011

56 Fan Y, Fan J, Ye M, Huang Z, Wang Y, Li Q and Huang J: Increased expression of microRNA-196a predicts poor prognosis in human ovarian carcinoma. Int J Clin Exp Pathol 8: 4132-4137, 2015.

57 Ohagi-Hara C, Sawada K, Kamiura S, Tomita Y, Isobe A, Hashimoto K, Kinose Y, Mabuchi S, Hisamatsu T, Takahashi T,Kumasawa K, Nagata S, Morishige K, Lengyel E, Kurachi H and Kimura T: miR-92a inhibits peritoneal dissemination of ovarian cancer cells by inhibiting integrin $\alpha 5$ expression. Am J Pathol 182: 1876-1889, 2013.

58 Kenny HA, Dogan S, Zillhardt M, Mitra A, Yamada SD, Krausz $\mathrm{T}$ and Lengyel E: Organotypic models of metastasis: a threedimensional culture mimicking the human peritoneum and omentum for the study of the early steps of ovarian cancer metastasis. Cancer Treat Res 149: 335-351, 2009.

59 Giancotti FG and Ruoslahti E: Integrin signaling. Science 285: 1028-1032, 1999.

60 Iorio MV, Visone R, Di Leva G, Donati V, Petrocca F, Casalini P, Taccioli C, Volinia S, Liu CG, Alder H, Calin GA, Menard $\mathrm{S}$ and Corce CM: MicroRNA signatures in human ovarian cancer. Cancer Res 67: 8699-8707, 2007.

61 Kanlikilicer P, Rashed MH, Bayraktar R, Mitra R, Ivan C, Aslan B, Zhang X, Filant J, Silva AM, Rodriguez-Aguayo C, Bayraktar E, Pichler M, Ozpolat B, Calin GA, Sood AK and Lopez-Berestein G: Ubiquitous release of exosomal tumor suppressor miR-6126 from ovarian cancer cells. Cancer Res 30: 1566-1576, 2016.

62 Mitra AK, Sawada K, Tiwari P, Mui K, Gwin K and Lengyel E: Ligand-independent activation of $\mathrm{c}-$ Met by fibronectin and $\alpha 5 \beta 1$ integrin regulates ovarian cancer invasion and metastasis. Oncogene 30: 1556-1576, 2011.

63 Strobel $\mathrm{T}$ and Cannistra SA: Beta1-integrin partly mediate binding of ovarian cancer cells to peritoneal mesothelium in vitro. Gynecol Oncol 73: 362-367, 1999.

64 Yeh YM, Chuang CM, Chao KC and Wang LH: MicroRNA138 suppresses ovarian cancer cell invasion and metastasis by targeting SOX4 and HIF-1 $\alpha$. Int J Cancer 133: 867-8778, 2013.

65 Scharer CD, McCabe CD, Ali-Seyed M, Berger MF, Bulyk ML and Moreno CS: Genome-wide promoter analysis oft he SOX4 transcriptional network in prostate cancer cells. Cancer Res 69: 709-717, 2009. 
66 Liao YL, Sun YM, Chau GY, Chau YP, Lai TC, Wang JL, Horng JT, Hsiao M and Tsou AP: Identification of SOX4 target genes using phylogenetic footprinting-based prediction from expression microarrays suggests that overexpression of SOX4 potentiates metastasis in hepatocellular carcinoma. Oncogene 27: 5578-5589, 2008.

67 Jin VV, Chen BB, Li YH, Zhu H, Huang M, Gu SM, Wang QQ, Chen JY, Yu S, Wu J and Shao ZM: TIEG1 inhibits breast cancer invasion and metastasis by inhibition of epidermal growth factor receptor (EGFR) transcription and the EGFR signaling pathway. Mol Cell Biol 32: 50-63, 2012.

68 Semenza GL: Targeting HIF-1 for cancer therapy. Nat Rev Cancer 3: 721-732, 2003.

69 Kurrey NK, K A and Bapat SA: Snail and Slug are major determinants of ovarian cancer invasiveness at the transcription level. Gynecol Oncol 98: 155-165, 2005.

70 Kinose Y, Sawada K, Nakamura K, Sawada I, Toda A, Nakatsuka E, Hashimoto K, Mabuch S, Takahashi S, Kurachi $\mathrm{H}$, Lengyel $\mathrm{E}$ and Kimura T: The hypoxia-related micrRNA miR-199a-3p displays tumor suppressor functions in ovarian carcinoma. Oncotarget 6: 11342-11356, 2015.

71 Joshi HP, Subramanian IV; Schnettler EK, Ghosh G, Rupaimoole R, Evans C, Saluja M, Jing Y, Cristina I, Roy S, Zeng Y, Shah VH, Sood AK and Ramakrishnan S: Dynamin 2 along with microRNA-199a reciprocally regulate hypoxiainducible factors and ovarian cancer metastasis. Proc Natl Avad Sci USA 111: 5331-5336, 2014.

72 Chen R, Alvero AB, Silasi DA, Kelly MG, Fest S,Visintin I, Leiser A, Schwartz PE, Rutherford T and Mor G: Regulation of IKKbeta by miR-199a affects NFkappaB activity in ovarian cancer cells. Oncogene 27: 4712-4723, 2008.

73 Barker HE, Cox TR and Erler JT: The rationale for targeting the LOX family in cancer. Nat Rev Cancer 12: 540-552, 2012.

74 Sawada K, radjabi AR, Shinomiya N, Kistner E, Kenny H, Becker AR, Turkyilmaz MA, Salgia R, Yamada SD, Vande Woude GF, Tretiakova MS and Lengyel E: c-Met overexpression is a prognostic factor in ovarian cancer and an effective target for inhibition of peritoneal dissemination and invasion. Cancer Res 67: 1670-1679, 2007.

75 Scagliotti GV, Novello S and von Pawel J: The emerging role of MET/HGF inhibitors in oncology. Cancer Treat Rev 39: 793 801, 2013.

76 Greten FR and Karin M: The IKK/NF-kappaB activation pathway - a target for prevention and treatment of cancer. Cancer Lett 206: 193-199, 2004.

77 Greten FR, Eckmann L, Greten TF, Park JM, Li ZW, Egan LJ, Kagnoff MF and Karin M: Ikkbeta links inflammation and tumorigenesis in a mouse model of colitis-associated cancer. J Exp Med 208: 1889-1900, 2011.

78 Balkwil F and Coussens LM: Cancer: an inflammatory link. Nature 431: 405-406, 2004.

79 Lam SS, Ip CK, Mak AS and Wong AS: A novel p70 S6 kinasemicroRNA biogenesis axis mediates multicellular spheroid formation in ovarian cancer progression. Oncotarget 7: 3806438077, 2016.

80 Derycke LD and Bracke ME: N-cadherin in the spotlight of cell-cell division, differentiation, embryogenesis, invasion and signalling. Int J Dev Biol 48: 463-476, 2004.

81 Hosano S, Karyiama H, Terauchi M, Shibata K, Ino K, Nawa A and Kikkawa F: Expression of Twist increases the risk für recurrence and for poor survival in epithelial ovarian carcinoma patients. Br J Cancer 96: 314-320, 2007.

82 Malki S, Bibeau F, Notarnicola C, Roques S, Berta P, Poulat F and Boizet-Bonhoure B: Expression and biological role of the prostaglandin D synthase/SOX9 pathway in human ovarian cancer cells. Cancer Lett 255: 182-193, 2007.

83 Kurzynska-Kokomiak A, Koralewska N, Pokornovska M, Urbanowicz A, Tworak A, Mickiwicz A and Figlerowicz M: The many faces of Dicer: the complexity of the mechanisms regulating DICER gene expression and enzyme activities. Nucl Acids Res 43: 4365-4380, 2015

84 Trabucchi M, Briata P, Garcia-Mayoral M, Haase AD, Filipowiecz W, Ramos A, Gherzi R and Rosenfeld MG: The RNA binding protein KSRP promotes biogenesis of a subset of microRNAs. Adv Exp Med Biol 700: 36-42, 2010.

85 Perez-Tenorio G, Karlsson E, Waltersson MA, Olsson B, Holmlund B, Nordenskjöld B, Fornander T, Skoog 1 and Stal O: Clinical potential of the mTOR targets S6K1 and S6K2 in breast cancer. Breast Cancer Res Treat 128: 713-723, 2011.

86 Lin KT, Yeh YM, Chuang CM, Yang SY, Chang JW, Sun SP, Wang YS, Chao KC and Wang LH: Glucocorticoids mediate induction of microRNA-708 to suppress ovarian cancer metastasis through targeting Rap1B. Nat Commun 6: 5917, 2015.

87 Gennari A, Salvadori B, Tognoni A and Conte PF: Rapid intravenous premedication with dexamethasone prevents hypersensitivity reactions to paclitaxel. Annal Oncol 7: 978979, 1996.

88 Huang M, Anand S, Murphy EA, Desgrosselier JS, Stupack DG, Shatti SJ, Schlaepfer DD and Cheresh DA: EGFRdependent pancreatic carcinoma cell metastasis through Rap1 activation. Oncogene 31: 2783-2793, 2012.

89 Bischoff A, Huck B, Keller B, Strotbek M, Schmid S, Boerries M, Busch H, Müller D and Olayioye MA: miR149 functions as a tumor suppressor by controlling breast epithelial cell migration and invasion. Cancer Res 74: 5256-5265, 2014.

90 Lin J, Zhang L, Huang H, Huang Y, Huang L, Wang J, Huang S, He L, Zhou Y, Jia W, Yun J, Luo R and Zheng M: MiR26/KPNA2 axis inhibits epithelial ovarian carcinoma proliferation and metastasis through downregulating OCT4. Oncotarget 6: 2393-23806, 2015.

91 Huang L, Wang HY, Li JD, Wang JH, Zhou Y, Luo RZ, Yun YP, Zhang $\mathrm{y}$, Jia WH and Zheng M: KPN2 promotes cell proliferation and tumorigenicity in epithelial ovarian carcinoma through upregulation of $\mathrm{c}-\mathrm{Myc}$ and downregulation of FOXO3a. Cell Death Dis 4: e745, 2013.

92 Li XL, Jia LL, Shi MM, Li X, Li ZH, Li HF, Wang EH and Jia XS: Downregulation of KPNA2 n non-small-cell lung cancer is associated with Oct4 expression. J Transl Med 11: $232,2013$.

93 Schöler HR, Ruppert S, Suzuki N, Chowdhury K and Gruss P: New type of POU domain in germ line-specific protein Oct4. Nature 344: 435-439, 1990.

94 Zheng M, Tang L, Huang L, Ding H, Liao wT, Zeng MS and Wang HY: Overexpression of karyopherin-2 in epithelial ovarian cancer and correlation with poor prognosis. Obstet Gynecol 116: 435-439, 2010.

95 Lv Y, Lei Y, Hu Y, Ding W, Zhang C and Fang C: miR-448 negatively regulates ovarian cancer cell growth and metastasis by targeting CXCL12. Clin Transl Oncol 17: 903-909, 2015. 
96 Sun X, Cheng G, Hao M, Zheng J, Zhou X, Zhang J, Taichman RS, Pienta KJ and Wang J: CXCL12/CXCR4/CXCR7 chemokine axis and cancer progression. Cancer Metastasis Rev 29: 709-722, 2010.

97 Domanska UM, Kruizing RC, Nagengast WB, Timmer-Bosscha $\mathrm{H}$, Huls G, de Vries EG and Walenkamp AM: A review on CXCR4/CXCL12 axis in oncology: no place to hide. Eur J Cancer 49: 219-230, 2013.

98 Mitra AK, Zillhardt M, Hua Y, Tiwari P, Murmann AE, Peter $\mathrm{ME}$ and Lengyel E: MicroRNAs reprogram normal fibroblasts to cancer-associated fibroblasts in ovarian cancer. Cancer Discov 2: 1100-1108, 2012.

99 Penna E, Orso F and Taverna D: miR-214 as a key hub that controls cancer networks: small player, multiple functions. I Invest Dermatol 135: 960-969, 2015.

100 Tsukishiro S, Suzumori N, Nishikawa H, Arakawa A and Suzumori K: Elevated RANTES levels in patients with ovarian cancer correlate with the extent of the disorder. Gynecol Oncol 102: 542-545, 2006.

101 Karnoub AE, Dash AB, Vo AP, Sullivan A, Brooks MW, Bell GW, Richardson AL, Polyak C, Tubo R and Weinberg RA: Mesenchymal stem cells within tumor stroma promote breast cancer metastasis. Nature 449: 557-563, 2007.

102 Zhang Y, Zhao FJ, Chen LL, Wang LQ, Nephew KP, Wu YL and Zhang S: MiR-373 targeting oft he Rab22a oncogene suppresses tumor invasion and metastasis in ovarian cancer. Oncotarget 5: 12291-12303, 2014.

103 Mesa R, Salomon C, Roggero M, Stahl PD and Mayorga LS: Rab22a affects the morphology and function of the endocytic pathway. J Cell Sci 114: 4041-4049, 2001.

104 Zech T and Machesky L: Rab5 and rac team up in cell motility. Cell 134: 18-20, 2008.

105 Mendoza P, Ortiz R, Dias J, Quest AF, Leyton L, Stupack D and Torres VA: Rab5 activation promotes focal adhesion disassembly, migration and invasiveness in tumor cells. J Cell Sci 126: 3835-3847, 2013

106 Torres VA, Mielgo A, Barbero S, Hsiao R, Wilkins JA and Stupak DG: Rab5 mediates caspase-8-promoted cell motility and metastasis. Mol Biol Cell 21: 369-376, 2010.

107 Hu H, Milstein M, Bliss JM, Thai Mm Malhotra G, Huynh LC and Colicelli J: Integration of transforming growth factor beta and RAS signaling silences a RAB5 guanine nucleotide exchange factor and enhances growth factor-directed cell migration. Mol Cell Biol 28: 1573-1583, 2008.

108 Mitra AK, Chiang CY, Tiwari P, Tmar S, Watters KM, Peter $\mathrm{ME}$ and Lengyel E: Microenvironment-induced downregulation of miR-193b drives ovarian cancer metastasis. Oncogene 34 : 5923-5932, 2015.

109 White EA, Kenny HA and Lengyel E: Three-dimensional modeling of ovarian cancer. Adv Drug Del Rev 15: 184-192, 2014.

110 Duffy MJ: The urokinase plasminogen activator system: role in malignancy. Curr Pharm Des 10: 39-49, 2004.

111 Blasi F: Urokinase and urokinase receptor. A parakrine/ autocrine system regulating cell migration and invasiveness. Bioessays 15: 105-111, 1993.

112 Sidenius N and Blasi F: The urokinase plasminogen activator system in cancer: recent advances and implication for prognosis and therapy. Cancer Metastasis Rev 22: 205-222, 2003.

113 Zhang W, Ling D, Tan J, Zhang J and Li L: Expression of urokinase plasminogen activator and plasminogen activator inhibitor type-1 in ovarian cancer and ist clinical significance. Oncol Rep 29: 637-645, 2013

114 Muralidhar GG and Barbolina MV: The miR-200 family: versatile players in epithelial ovarian cancer. Int J Mol Sci 16: 16833-16847, 2015.

115 Park SM, Gaur AB, Lengyel E and Peter ME: The miR-200 family determines the epithelial phenotype of cancer cells by targeting the E-cadherin repressors ZEB1 and ZEB2. Genes Dev 22: 894-907, 2008.

116 Korpal M and Kang Y: The emerging role of miR-200 family of microRNAs in epithelial-mesenchymal transition and cancer metastasis. RNA Biol 5: 115-119, 2008.

117 Gregory PA, Bracken CP, Bert AG and Goodall GJ: microRNAs as regulators of epithelial-mesenchymal transition. Cell Cycle 7: 3112-3118, 2008.

118 Zaman MS, Maher DM, Khan S, Jaggi M and Chauhan SC: Current status and implications of microRNAs in ovarian cancer diagnosis and therapy. J Ovarian Res 5: 44, 2012.

119 Sulaiman SA, Ab Mutalib NS and Jamal R: miR-200c regulation of metastases in ovarian cancer. potential role in epithelial and mesenchymal transition. Front Pharmacol 7: 271, 2016.

120 Bendoraite A, Knouf EC, Garg KS, Parkin RK, Kroh EM, O'Briant KC, Ventura AP, Godwin AK, Karlan BY, Drescher $\mathrm{CW}$, Urban N, Knudson BS and Tewari M: Regulation of miR200 family microRNAs and ZEB transcription factors in ovarian cancer evidence supporting a mesothelial-to-epithelial transition. Gynecol Oncol 116: 117-125, 2010.

121 Chen D, Zhang Y, Wang J, Chen J, Yang C, Cai K, Wang X, Shi $F$ and Dou J: MicroRNA-200c overexpression inhibits tumorigenicity and metastasis of $\mathrm{CD} 117{ }^{+} \mathrm{CD} 44^{+}$ovarian cancer stem cells by regulating epithelial-mesenchymall transition. J Ovarian Res 6: 50, 2013

122 Le MT, Hamar P, Guo C, Basar E, Perdigao-Henriques R, Balaj L and Lieberman J: miR-200-containing extracellular vesicles promote breast cancer cell metastasis. J Clin Invest 124: 51095128,2014

123 Sossey-Alaoui K, Bialkowska K and Plow EF: The miR200 family of microRNAs regulates WAVE3-dependent cancer cell invasion. J Biol Chem 284: 33019-33029, 2009.

124 Zhou X, Hu Y, Dai L, Wang Y, Wang W, Di W and Qiu L: MicroRNA-7 inhibits tumor metastasis and reverses epithelialmesenchymal transition through AKT/ERK1/2 inactivation by targeting EGFR in epithelial ovarian cancer. PLoS One 9: e96718, 2014.

125 Qiu L, Zhou C, Sun Y, Di W, Scheffler E, Healey S, Kouttab $\mathrm{N}$, Chu W and Wan Y: Crosstalk between EGFR and TrkB enhances ovarian cancer cell migration and proliferation. Int $\mathrm{J}$ Oncol 29: 1003-1011, 2006.

126 Webster RJ, Giles KM, Price KJ, Zhang PM and Mattick JS: Regulation of epidermal growth factor receptor signaling in human cancer cells by microRNA7. J Biol Chem 284: 5731-5741, 2009.

127 Li R, ShiX, Ling F, wang C, Liu J, Wang W and Li M: MiR34a suppresses ovarian cancer proliferation and motility by targeting AXL. Tumor Biol 36: 7277-7283, 2015.

128 Gay CM, Balaji K and Byers LA: Giving AXL the axe: targeting AXL in human malignancy. Br J Cancer 116: 415-423, 2017.

129 Li P, Sun Y and Liu Q: MicroRNA-340 induces apoptosis and inhibits metastasis of ovarian cancer cells by inactivation of NFkB1. Cell Physiol Biochem 38: 1915-1927, 2016. 
130 Karin $M$ and Ben-Neriah Y: Phosphorylation meets ubiquitination: the control of NFkB activity. Ann Rev Immunol 18: 621-663, 2000.

$131 \mathrm{Yu}$ Y, Wan Y and Huang C: The biological functions of NF-kB1 (p50) and its potential as an anti-cancer agent. Curr Cancer Drug Targets 9: 566-571, 2009.

132 Wen Z, Zhao S, Liu Y, Li X and Li S: MicroRNA-148a inhibits migration and invasion of ovarian cancer via targeting sphingosine-1-phosphate receptor 1. Mol Med Rep 12: 37753780, 2015.

133 Dai L, Xia P and Di W: Sphingosine 1-phosphate: a potential molecular target for ovarian cancer therapy? Cancer Invest 32 : 71-80, 2014.

134 Smicun Y, Reierstad S, Wang FQ, Lee C and Fishman DA: S1P regulation of ovarian carcinoma invasiveness. Gynecol Oncol 103: 952-959, 2006.

135 Zhou X, Zhao F, Wang ZN, Song YX, Chang H , Chiang Y and $\mathrm{Xu}$ HM: Altered expression of miR-152 and miR-148a in ovarian cancer is related to cell proliferation. Oncol Rep 27: 447-454, 2012

136 Yao L, Wang L, Li F, Gao X, Wei X and Liu Z: miR181c inhibits ovarian cancer metastasis and progression by targeting PKRCD expression. Int J Clin Med 8: 15198-15205, 2015.

137 Gonelli A, Mischiati G, Guerrini R, Voltan R, Salvadori S and Zauli G: Perspectives of protein kinase C (PKC) inhibitors as anticancer agents. Mini Rev Med Chem 9: 498-509, 2009.

138 Piccolo S, Cordonesi M and Dupont S: Molecular pathways: YAP and TAZ take center stage in organ growth and tumorigenesis. Clin Cancer Res 19: 4925-4930, 2013.

139 Harvey KF, Zhang X and Thomas DM: The Hippo pathway and cancer. The Hippo pathway and human cancer. Nat Rev Cancer 13: 246-257, 2013.

140 Pan Y, Robertson G, Pedersen 1, Lim E, Hernandez-Herrera A, Rowat AC, Patil SL, Chan CK, Wen Y, Zhang X, Basu-Roy U, Mansukhani A, Ch A, Sipahimalani P, Bowlby R, Brooks D, Thiessen N, Coarfa C, Ma Y, Moore RA, Schein JE, Mungall AJ, Liu J, Pecot CV, Sood AK, Jones SJ, Marra MA and Gunaratne PH: miR-509-3p is clinically significant and strongly attenuates cellular migration and multi-cellular spheroids in ovarian cancer. Oncotarget 7: 25930-25948, 2016.

141 Dupont S, Morsut L, Aragona M, Enzo E, Giulitti S, Cordenosi M, Zanconato F, Le Diagabel J, Forcato M, Bicciato S, Elvassore $\mathrm{N}$ and Piccolo S: Role of YAP/TAZ in mechanotransduction. Nature 474: 179-183, 2011.

142 Halder G, Dupont S and Piccolo S: Transduction of mechanical and cytoskeletal cues by YAP and TAZ. Nat Rev Mol Cell Biol 13: 591-600, 2012.

143 Eyckmans J, Boudou T, Yu X and Chen CS: A hitchhiker's guide to mechanobiology. Dev Cell 21: 35-47, 2011.

144 Guo F, Cogdell D, Hu L, Yang D, Sood AK, Xue F and Zhang $\mathrm{W}$ : miR-101 suppresses the epithelial-to-mesenchymal transition by targeting ZEB1 and ZEB2 in ovarian carcinoma. Oncol Rep 31: 2021-2028, 2014.
145 Song N, Liu H, Ma X and Zhang S: Placental growth factor promotes metastases of ovarian cancer through miR-543regulated MMP7. Cell Physiol Biochem 37: 1194-1112, 2015.

146 Tanimoto H, Underwood LJ, Shigemasa K, Parmley TH, Wang Y, Yan Y, Clarke J and O'Brien TJ: The matrix metalloprotease pump-1 (MMP-7, Matrilysin): A candidate marker/target for ovarian cancer detection and treatment. Tumor Biol 20: 88-98, 1999.

147 Wang FQ, So J, Reierstad S and Fishman DA: Matrilysin (MMP-7) promotes invasion of ovarian cancer cells by activation of progelatinase. Int J Cancer 114: 19-31, 2005.

148 Yang Y, Jiang Y, Wan Y, Zhang L, Qui J, Zhou S and Cheng W: UCA1 cfunctions as a competing endogenous RNA to suppress epithelial ovarian cancer metastasis. Tumor Biol 37: 1063310641, 2016.

149 Davidson B, Trope CG and Reich R: The clinical and diagnostic role of microRNAs in ovarian carcinoma. Gynecol Oncol 133: 640-646, 2014

150 Gambari R, Brognara E, Spandidos DA and Fabbri E: Targeting oncomiRNAs and mimicking tumor suppressor miRNAs: New trends in the development of miRNA therapeutic strategies in oncology (Review). Int J Oncol 49: 5-32, 2016.

151 Ling H, Fabbri M and Calin GA: MicroRNAs and other noncoding RNAs as targets for anticancer drug development. Nat Rev Drug Discov 12: 847-865, 2013.

152 Wang Z: The principles of miRNA-masking antisense oligonucleotiudes technology. Methods Mol Biol 676: 43-49, 2011.

153 Goldberg MS: siRNA delivery for the treatment of ovarian cancer. Methods 63: 95-100, 2013.

154 Armstrong DK, Bundy B, Wenzel L, Huang HQ, Baergen R, Lele S, Copeland LJ, Walker JLand Burger RA: Intraperitoneal cisplatin and paclitaxel in ovarian cancer. N Engl J Med 354: 34-43, 2006.

155 Miyagi Y, Fujiwara K, Kigawa J, Itamochi H, Nagao S, Aotani $\mathrm{E}$, Terakawa $\mathrm{N}$ and Kohno I: Intraperitoneal carboplatin infusion may be a pharmacologically more reasonable route than intravenous administration as a systemic chemotherapy. A comparative pharmacokinetic analysis of platinum using a new mathematical model after intraperitoneal $v s$. intravenous infusion of carboplatin - a Sankai Gynecologx Study Group (SGSG) study. Gynecol Oncol 99: 591-596, 2005.

156 Weidle UH, Birzele F, Kollmorgen $G$ and Rüger R: Mechanisms and targets involved in dissemination of ovarian cancer. Cancer Genomics Proteomics 13: 407-423, 2016.

Received September 7, 2017

Revised October 9, 2017

Accepted October 17, 2017 